Running Head: UNFAIR TREATMENT, RETALIATION, AND SELF-REGULATION

Retaliation as a Response to Procedural Unfairness: A Self-Regulatory Approach

\author{
Lieven Brebels and David De Cremer \\ Tilburg University
}

Constantine Sedikides

University of Southampton

Correspondence can be addressed to Lieven Brebels, Department of Social Psychology, Tilburg University, PO Box 90153, 5000 LE Tilburg, The Netherlands.

Email: L.brebels@UvT.nl. Phone: 00311346681 81. Fax: 0031134662067. 


\begin{abstract}
When does procedural unfairness result in retaliation, and why do unfair-treatment recipients sometimes pursue and other times inhibit retaliation? Five studies addressed these questions. We proposed and found that regulatory focus moderates retaliation against an unfairness-enacting authority: Promotion-focus participants were more likely to retaliate than prevention-focus participants. Promotion focus was associated with, and also heightened the accessibility of, the individual self. In turn, individual-self accessibility influenced retaliation. In fact, preventionfocus participants were as retaliatory as promotion-focus participants under conditions of high individual-self accessibility. Implications for the procedural fairness and regulatory focus literatures are discussed and suggestions for future research are offered.
\end{abstract}

Keywords: retaliation, unfair treatment, procedural fairness, regulatory focus, self-activation 


\section{Retaliation as a Response to Procedural Unfairness: A Self-Regulatory Approach}

For many people, unfair treatment in group or organizational settings is a recurrent experience; it is also an aversive experience (Mikula, 1986; Miller, 2001; Oyserman, Uskul, Yoder, Nesse, \& Williams, 2007). Aversion would be expected to result in retaliation (e.g., revenge, stealing, antisocial resource allocation). Indeed, justice researchers have considered perceived unfairness a key predictor of retaliation in employee-supervisor relationships, and they have carried out field studies to test this idea (Aquino, Tripp, \& Bies, 2001; Barclay, Skarlicki, \& Pugh, 2005; Bies, Tripp, \& Kramer, 1997; Blader, Chang, \& Tyler, 2001; Giacalone \& Greenberg, 1997; Greenberg, 1993; Skarlicki \& Folger, 1997). When these studies were metaanalyzed (Colquitt, Conlon, Wesson, Porter, \& Ng, 2001), however, a rather surprising conclusion emerged: perceived unfairness was an inconsistent predictor of retaliation. This conclusion was echoed by subsequent bodies of research (Bembenek, Beike, \& Schroeder, 2007; Colquitt, Scott, Judge, \& Shaw, 2006; Posthuma, Maertz, \& Dworkin, 2007). In the words of Colquitt et al. (2006), "a substantial amount of variation exists in these relationships, and ... moderators could explain much of that variation (p. 111)." It appears, then, that researchers lack a clear understanding of when perceived unfairness translates into retaliation and why unfairness recipients pursue or inhibit retaliation.

Some justice research has looked into affect as an explanation for the inconsistent relation between unfair treatment and retaliation (Barclay, Skarlicki, \& Pugh, 2005; Bembenek et al., 2007; Bies \& Tripp, 1996; De Cremer, 2007). This research has shown that negative emotions (e.g., anger, disappointment) accompany retaliation as a response to perceived unfairness, but the research has not addressed when and why people sometimes pursue and sometimes inhibit retaliation. This is what we set to do in the present article. We addressed the "when" question by examining the moderational role of regulatory focus in Studies 1 and 2. We 
address the "why" question by examining the correlational or causal role of self-activation in Studies 3-5. We now turn to a discussion of regulatory focus and self-activation.

\section{On Regulatory Focus and Self-Activation}

Procedural fairness refers to the degree to which the process on which enacting authorities rely to make decisions is perceived as fair by group members or employees (Lind \& Tyler, 1988; Van den Bos, 2007). Procedural fairness is typically operationalized in terms of the implementation of transparent and valid decision-making rules (e.g., accuracy) and in terms of providing group members or employees with an opportunity for input into the decision-making process (i.e., voice). Despite the fact that procedural unfairness threatens recipients' needs for control, self-esteem, certainty, and belongingness (De Cremer \& Tyler, 2005; Tyler \& Lind, 1992; Sedikides, De Cremer, Hart, \& Brebels, in press; Van den Bos \& Lind, 2002), while challenging their values and moral beliefs (Folger, 2001; Lerner, 2002; Skitka, 2002), responses to it have been rather inconsistent (Bembenek et al., 2007; Colquitt et al., 2001; Posthuma et al., 2007). We propose that the manner in which recipients regulate the pursuit of their goals (i.e., regulatory focus) provides an explanation for the inconsistency in retaliatory responses to procedural unfairness.

According to regulatory focus theory (Higgins, 1998; Higgins et al., 2001; Idson \& Higgins, 2000), there are two functionally distinct motivational systems that guide goal pursuit. Nurturance concerns (e.g., accomplishments, hopes, aspirations) activate and are best met through a promotion focus, whereas security concerns (e.g., duties, responsibilities, obligations) activate and are best met through a prevention focus. Importantly, promotion and prevention foci are associated with different strategies for goal pursuit. Promotion-focus strategies involve goal pursuit in a willful or approach-oriented manner, and involve achievement through immediate action rather than reflective deliberation. These strategies are pronounced among persons who have an independent self-construal (Lee, Aaker, \& Gardner, 2000), are guided by autonomous 
goal setting (Meyer, Becker, \& Vandenberghe, 2004), and are attuned to intrinsic needs (VanDijk \& Kluger, 2004). In contrast, prevention-focus strategies involve goal-pursuit in a vigilant or avoidance-oriented manner, and involve careful assessment of the social context and action consequences. These strategies are pronounced among persons who have an interdependent selfconstrual, are guided by situational goal-setting, and are susceptible to social pressure (Lee et al., 2000; Meyer et al., 2004; Van-Dijk \& Kluger, 2004). In the context of the present research, we generally expected that the behavior of promotion-focus (vs. prevention-focus) persons would be guided more strongly by their inner states and less strongly by normative expectations.

Despite a burgeoning literature linking regulatory focus to intrapersonal behavior and task performance (Crowe \& Higgins, 1997; Friedman \& Förster, 2001; Higgins et al., 2001; Idson, Liberman, \& Higgins, 2000; Seibt \& Förster, 2004), relatively little research has examined the role of regulatory focus in interpersonal relationships. This point is particularly relevant to the scope of the present research, given that procedural fairness is generally portrayed as an interpersonal or social interaction phenomenon (Greenberg, 1996; Lind \& Tyler, 1988; Skitka, 2003). Thus, examining the role of regulatory focus in the procedural fairness arena promises not only to inform when and why retaliatory responses to unfair treatment emerge but also to increase understanding of how regulatory focus works in a social interaction context.

The available evidence, albeit in short supply, forms the backbone of our claim that regulatory focus moderates responses to unfair treatment in social interactions. First, recent research has shown that approach rather than avoidance motivation is involved in perceptions of procedural fairness (i.e., provision of voice; Van Prooijen, Karremans, \& Van Beest, 2006), suggesting that attainment strivings (e.g., enhancing self-esteem) rather than evasion strivings (e.g., reducing fear of exploitation) affect judgments of procedural fairness. These findings are generally consistent with a possible moderational role for regulatory focus. At the same time though, this research, contrary to ours, (a) has conceptualized and operationalized procedural 
fairness as a dependent rather than an independent variable, (b) has been concerned with approach and avoidance motivation rather than self-regulatory focus, and (c) has not examined how people cope with procedural unfairness as a function of goal regulation (i.e., regulatory focus). Second, both approach motivation and promotion focus are related to greater leftprefrontal cortical activity (Amodio, Shah, Sigelman, Brazy, \& Harmon-Jones, 2004; HarmonJones \& Allen, 1998; Sutton \& Davidson, 1997; for an exception, see Friedman \& Förster, 2005), which, in turn, is associated with retaliation following provocation (Harmon-Jones \& Sigelman, 2001). These findings suggest a link between promotion-focus and retaliation. Third, prevention-focus strength is positively related to self-silencing, withdrawal, and inhibition of hostile behavior in the face of unfairness or rejection (Ayduk, May, Downey, \& Higgins, 2003; Oyserman et al., 2007, Study 3). Although this research (a) was concerned with unfair treatment (i.e., social rejection, stereotype threat) rather than procedural unfairness, and (b) pertained to anticipation rather than actual experience of unfair situations, it nevertheless raises the possibility that prevention-focus individuals favor withdrawal rather than retaliation as an immediate response to unfairness. In all, based on insights from the above-reviewed research, we hypothesized that promotion-focus participants would be more likely to retaliate against an authority's unfair treatment than prevention-focus participants. This is the "when" question that we addressed in Studies 1 and 2.

Somewhat more direct evidence for the role of promotion focus in social interaction comes from face-to-face negotiation research (Galinsky et al., 2005). Participants with dispositional or temporarily-activated promotion (relative to prevention) focus made more aggressive opening offers. Interestingly, these participants reported that they paid increased attention to their personal target prices. Relatedly, in a self-evaluation study, promotion focus led to higher accessibility of self-esteem relevant words (Leonardelli, Lakin, \& Arkin, 2007). Finally, participants who fail to attain their promotion (but not prevention) goals report lower 
self-esteem (Moretti \& Higgins, 1990). Promotion focus, then, is associated with, or heightens the accessibility of, personal interest or self-esteem. Stated otherwise, promotion focus is associated with, or heightens, the accessibility of the individual self (Brewer \& Gardner, 1996; Sedikides \& Brewer, 2001a).

The individual self refers to the set of traits and characteristics that are unique to the person. These attributes differentiate the person from close others and, more generally, from ingroup members (Gaertner \& Sedikides, 2005; Gaertner, Sedikides, Luke, \& Iuzzini, 2008; Sedikides \& Brewer, 2001b). The individual self is associated with self-enhancement and selfdefense motivation (Sedikides \& Gregg, 2003, 2008; Sedikides \& Strube, 1997). When this type of self is accessible, the person is likely to construe social interactions in a competitive than cooperative manner, to be attuned to available gains, and to behave spontaneously and opportunistically in a way that safeguards or maximizes short-term (rather than long-term) interest (Gaertner, Sedikides, \& Graetz, 1999; Gaertner, Sedikides, Vevea, \& Iuzzini, 2002; Stapel \& Van der Zee, 2006). Indeed, accessibility of the individual self has been linked to selfbased or opportunistic responding in the area of justice as well (Miedema, Van den Bos, \& Vermunt, 2006; Skitka, 2002, 2003; Skitka \& Bravo, 2005; Van den Bos \& Miedema, 2000).

Based, then, on findings that link (a) promotion focus to the individual self (Galinsky et al., 2005; Leonardelli et al., 2007; Moretti \& Higgins, 1990), and (b) accessibility of the individual self to short-term and opportunistic behavior (Gaertner et al., 2002, 2008; Stapel \& Van der Zee, 2006), and (c) accessibility of the individual self to opportunistic responding in justice settings (Miedema et al., 2006; Skitka \& Bravo, 2005), we hypothesized that a reason why promotion-focus participants would behave in a retaliatory manner would be the relatively high (chronic or temporary) accessibility of the individual self. This is the "why" question that we addressed in Studies 3-5.

The Present Research 
The present research consists of five studies and addresses three waves of programmatically-driven issues. As a first step, we proposed that retaliation to unfair treatment is moderated by regulatory focus. Evidence suggests that promotion-focus strategies are associated with a direct, whereas prevention-focus strategies with a conformist, behavioral style. Thus, we hypothesized that promotion-focus, but not prevention-focus, participants would retaliate against an authority who is perceived as enacting unfair procedures. We tested this hypothesis in Studies 1 and 2.

As a second step, we drew on insights from the regulatory focus literature to identify and test a mechanism deemed responsible for the moderational role of regulatory focus in retaliatory responding to unfairness. We have reviewed research showing that promotion-focus strategies are adopted by persons who pursue their goals in a relatively independent, autonomous, and intrinsic manner (Lee et al., 2000; Meyer et al., 1998; Van Dijk \& Kluger, 2004). This aligns well with other research indicating that promotion (relative to prevention) focus is associated with personal concerns (Galinsky et al., 2005), accessibility of esteem-related words (Leonardelli et al., 2007), and variations in self-esteem (Moretti \& Higgins, 1990). The cumulative body of evidence, then, suggests that promotions focus is associated with, or heightens, the accessibility of the individual self (Gaertner et al., 2002; Sedikides \& Brewer, 2001a). We tested this idea in Study 3 .

As a third step, we examined whether heightened accessibility of the individual self differentially predicts retaliation to unfair treatment among promotion-focus and preventionfocus persons. Evidence suggests that, when the individual self is accessible, the person perceives social interactions as competitive and behaves opportunistically so that she or he maximizes short-term personal interest (Gaertner \& Sedikides, 2005; Gaertner et al., 2008; Stapel \& Van der Zee, 2006). On the basis of this evidence, we hypothesized that the accessibility of the individual self would be a reason why promotion-focus participants opt for 
retaliative action (Miedema et al., 2006; Skitka, 2003). We tested this hypothesis by rendering the individual self accessible through heightened self-attention (Study 4) and uniqueness/authenticity feedback (Study 5).

Central to regulatory focus theory is that people not only differ in the extent to which they are dispositionally predisposed to promotion-focus versus prevention-focus goals (Lockwood, Jordan, \& Kunda, 2002), but also that situational or priming cues can induce distinct regulatory foci (Friedman \& Förster, 2001; Idson et al., 2000; Oyserman et al., 2007). Therefore, we assessed regulatory focus either as a dispositional difference (Studies 2 and 4) or as a momentarily-activated construct (Studies 1, 3, and 5).

The dependent variable of interest was retaliation towards the unfairness enacting authority. This variable took the form of stealing from the authority's earnings (Greenberg, 1993 ) in Study 1, and fairness violations in resource allocations at an Ultimatum Bargaining Game (UBG; Güth, Schmittberger, \& Schwarze, 1982) in Studies 2, 4, and 5.

Furthermore, we operationalized procedural fairness in terms of the accuracy rule. As mentioned previously, accuracy refers to whether organizational procedures (e.g., task assignments, hiring or promotion practices) are perceived as transparent and valid in the use of information available for decision-making (Leventhal, 1980). Recipients perceive inaccurate procedures as more unfair than accurate ones (De Cremer, 2004; De Cremer \& Sedikides, 2005; Van den Bos, Bruins, Wilke, \& Dronkert, 1999). Moreover, accuracy violations indicate a lack of recognition for recipients' performance or effort, which represents one of the most frequently reported unfairness experiences in daily life (Mikula, 1986).

Participants in all studies were undergraduate students at Tilburg University. They were randomly assigned to experimental conditions. Cell sizes were approximately even. Also, at the end of each study session, participants were thanked, debriefed, and remunerated where relevant. 
Given that prior research (Bettencourt \& Miller, 1996) has suggested a link between gender and retaliation, we included gender as a covariate in all reported analyses. A gender main effect was obtained only in Studies 1 and 2: Men behave more retaliatorily than women. However, in none of our studies did gender interact with the independent variables or predictors. Therefore, we will omit further discussion of gender effects.

\section{Study 1}

Study 1 is the first test of the hypothesis that regulatory focus moderates retaliation to unfair treatment. Participants became involved in a laboratory-based social interaction. In particular, they engaged in a screening task for a role assignment in their group. Next, they received procedural feedback from the decision-making authority. Finally, they were presented with an opportunity to steal from the authority's earnings.

We induced regulatory focus with a priming technique pioneered by Idson et al. (2000). To ascertain that regulatory focus could not interfere with effort or performance on the screening task, we primed participants after this task and before the procedural fairness manipulation. We hypothesized that retaliation (i.e., stealing from the authority's earnings) would generally be a function of procedural fairness, but this effect would be localized among promotion-focus participants.

\section{Method}

Participants and design. One hundred sixteen persons (72 females, 44 males; $\mathrm{M}_{\mathrm{age}}=$ $20.73, S D=2.63)$ were each paid $€ 7(\$ 10)$ for their participation. The design was a 2 (regulatory focus: prevention vs. promotion) x 2 (procedural fairness: accurate vs. inaccurate procedure) between-subjects factorial.

Experimental procedure. Participants signed up for an alleged study on "group dynamics." They were placed in adjacent cubicles containing a table, a chair, and a six-page booklet. At the beginning of each session, the experimenter explained via an intercom that 
participants would form a dynamic group in order to carry out a decision-making task. A dynamic group was said to consist of members taking on different roles. In order to form such a group, participants became involved in a screening task that occupied them for approximately 20 minutes. The task consisted of a test-battery, with five tests. The task was said to be a valid and accurate method to determine which role would best suit each group member. Next, participants were instructed to start reading the booklet.

On the first page of the booklet, participants read a short description of group roles. They learned that these roles would differ only according to content and not status or personal privileges. They also learned that someone else in the laboratory was assigned to grade their tests and, subsequently, to decide how the group roles would be allocated. This person was referred to as Manager A. The five remaining pages contained the actual test-battery: a Management Assessment Inventory, a Self-Assessment Tool, a test assessing Closeness to Others in General, a Self-Perception Questionnaire, and an Organizational Sociogram Structure Task. Upon completion of these tests, participants contacted the experimenter via an intercom, who then went to each cubicle, collected the responses, and ostensibly handed them over to Manager A.

While waiting for feedback, participants received a new, three-page booklet. This booklet, allegedly a filler task, was actually the regulatory focus manipulation. In the promotionfocus condition, participants described three accomplishment, hopes or aspirations and, following each description, listed several strategies they were using or planned to use in order to attain these goals. Participants in the prevention-focus condition completed a similar task, but for three responsibilities, duties or obligations. Next, participants contacted the experimenter via the intercom who collected the responses.

The procedural fairness manipulation ensued. The manipulation was based on the accuracy rule and modeled after prior studies that manipulated this aspect of procedural fairness (De Cremer, 2004; Van den Bos, Vermunt, \& Wilke, 1997). More specifically, each participant 
was given an envelope, which contained the manager's feedback in handwritten form. In the accurate procedure condition, participants read:

Hi, I received your test battery and looked it over. I have read and graded all parts. I will soon decide, based on all five parts, to which group role I will allocate you

Best, Manager A

In the inaccurate procedure condition, participants read:

Hi, I received your test battery. I have read and graded only one part. (I did not look at the other four parts.) I will soon decide, based on the single part I read and graded, to which group role I will allocate you.

\section{Best, Manager A}

We proceeded to collect the manipulation checks and dependent measures. Participants responded to all items on 7 -point scales $(1=$ not at all, $7=$ very much so $)$. To check the perceived accuracy of the procedural fairness manipulation, we asked participants: "To what extent did Manager A make the decision in an accurate manner?". To check whether the manipulation affected perceived fairness, we asked participants: "To what extent were you treated fairly by Manager A?”.

Lastly, to assess retaliation, participants were told that, at the end of the study, Manager A would be paid for his or her time. The research budget included a maximum wage of $€ 25$, but every participant had the opportunity to take away a minimum of 0 and a maximum of 200 eurocents (i.e., $€ 0-2$ ). It was made clear to them that their decisions would be taken into account to calculate the manager's actual earnings. Then, each participant indicated how many eurocents, if any, they took away from the manager's payment.

\section{Results and Discussion}

Manipulation checks. Two judges independently coded participants' goal descriptions as either promotion focus or prevention focus (The constructs were defined for them.). The judges 
agreed on $92 \%$ of the descriptions $($ Kappa $=.84)$. Disagreement was low and virtually equal in the promotion focus $(7 \%)$ and prevention focus $(9 \%)$ conditions. This indicates that participants followed the instructions, as intended. Disagreements between judges were resolved with discussion and the resolutions were included in the analyses.

A $2 \times 2$ ANOVA on perceived accuracy yielded a procedural fairness main effect, $F(1$, $111)=224.61, p<.001, r=.81,95 \% C I[-3.74 ;-2.52]$. Participants in the accurate procedure condition $(M=5.53, S D=1.12)$ considered the enacted procedure as more accurate than those in the inaccurate procedure condition $(M=2.32, S D=1.18)$. No other effect was significant.

Likewise, the 2 × 2 ANOVA on perceived fairness yielded a procedural fairness main effect, $F(1,111)=168.78, p<.001, r=.77,95 \% C I[-4.04 ;-2.66]$. Participants in the accurate procedure condition $(M=5.49, S D=1.25)$ reported that they were treated more fairly than those in the inaccurate procedure condition $(M=2.35, S D=1.33)$. Again, no other effect was significant. The procedural fairness manipulation was effective.

Retaliation. A 2 × 2 ANOVA on stealing yielded a procedural fairness main effect, $F(1$, $111)=21.22, p<.001, r=.39,95 \% C I[55.95 ; 134.94]:$ Participants in the inaccurate procedure condition $(M=160, S D=66)$ stole more money from the manager than those in the accurate procedure condition $(M=99, S D=86)$. Importantly, the hypothesized interaction emerged, $F(1$, $111)=5.15, p<.01, r=.20,95 \% C I[-118.46 ;-8.00]$ (Figure 1). Simple effects tests revealed that the procedural fairness main effect was significant in the promotion-focus condition, $F(1$, $111)=22.55, p<.001, r=.41$, but not in the prevention-focus condition, $F(1,111)=2.42, p>$ $.12, r=.14$. Participants in the promotion-focus condition were more likely to steal from an unfair manager than participants in the prevention-focus condition. Alternatively, the regulatory focus main effect was significant in the unfair, $F(1,111)=4.20, p<.05, r=.19$, but not in the fair procedure condition, $F(1,111)<1, p>.32, r=.09$. Stealing was predicted by regulatory focus in the case of unfair treatment. 
Summary. These findings provide preliminary evidence that regulatory focus moderates retaliation to unfair treatment. Participants generally behaved more retaliatorily when they were treated unfairly than fairly, but this effect was localized in the promotion-focus condition. Importantly, these results were obtained with momentarily-activated (instead of dispositional) differences in regulatory focus and by assessing one specific type of retaliation (i.e., stealing).

\section{Study 2}

In Study 2, we attempted to replicate Study 1 findings with a dispositional rather than momentarily-activated measure of regulatory focus. Also, in Study 1, we operationalized retaliation as stealing from the enacting authority's earnings. A possible limitation of this measure is its relative ambiguity. All participants took away at least some money, arguably indicating that there was no clearly defined norm as to exactly how retaliatory this behavior was. We addressed this potential limitation in Study 2 by using a normatively established measure of retaliation.

In particular, we examined offers in an UBG. In this game, the prosocial offer or normative allocation is a 50-50 split, whereas the antisocial offer is lower than the equal split (e.g., 60-40 distribution; Güth et al., 1982; Handgraaf, Van Dijk, \& De Cremer, 2003). In the UBG that we used, participants made an offer to the supervisor, who had previously treated them either in an unfair or fair manner. This supervisor was the recipient and had the option of either accepting or rejecting the proposed offer. If the supervisor accepted, the offer would stand; if the supervisor rejected, neither party would get anything. Thus, making the supervisor an antisocial offer would be clearly regarded as retaliation toward him or her. We hypothesized that participants would be more likely to make antisocial offers when treated unfairly than fairly. However, this effect would be driven by promotion-focus participants.

\section{Method}


Participants and design. Seventy one persons (40 females, 31 males; $\mathrm{M}_{\mathrm{age}}=20.62, S D=$ 2.46) were paid $€ 2$ (\$2.85) for participation. We assessed individual differences in regulatory focus, manipulated procedural fairness (accurate vs. inaccurate procedure), and assessed behavior (i.e., UBG offers).

Material and procedure. Participants completed the regulatory focus scale (Ms $=4.99$ vs. $3.81 ; S D s=.75$ vs. .88 for the promotion and prevention focus subscales respectively). The two subscales were uncorrelated $(r=.08, p>.48)$. We created a dominant regulatory focus scale by subtracting the prevention-focus $(\alpha=.75)$ from the promotion-focus $(\alpha=.75)$ subscale. The resulting scale was correlated with both the promotion focus $(r=.61, p<.001)$ and the prevention focus $(r=-.74, p<.001)$ subscales. High scores reflected a promotion focus, low scores a prevention focus.

The procedural fairness manipulation ensued. This manipulation was modeled after Van den Bos, Vermunt, and Wilke (1997). Participants imagined the following scenario: Synalco Medics, a large medical logistics company, has many employees working for them. You are also an employee at this company. This week, you learned that there will be a possibility for job promotion in your own department for employees who have the same expertise as you do. To find out if you qualify for promotion, you were required to go through a company procedure. This selection procedure consists of a 9-part testbattery: an intelligence test, a personality test, a mathematical test, a test measuring your technical skills, a test assessing your calculation skills, a language test, a test for presentation skills, a motivation test, and, finally, an interview with the supervisor. Next, participants received different information, depending on the procedural fairness condition to which they were assigned. Participants in the accurate procedure condition read: Today, you find out that your supervisor graded all nine parts of the selection procedure. Based on these grades, your supervisor will soon decide who gets the promotion. 
Participants in the inaccurate procedure condition read:

Today, you find out that your supervisor graded only one of the nine parts of the selection procedure. Based on this grade, your supervisor will soon decide who gets the promotion. Then, we collected the manipulation check measures. Participants responded to these items on a 7-point scale $(1=$ not at all, $7=$ very much so $)$. To check for the effectiveness of the accuracy manipulation, we asked participants: "To what extent do you consider the decisionmaking procedure as accurate?". To check for fairness perceptions, we asked participants three questions: "How fairly were you treated by the supervisor?", "How respectfully were you treated by the supervisor?", and "To what extent were you treated justly?". We combined these items to form a fairness perceptions scale $(\alpha=.94)$.

Then, we introduced the UBG. Participants learned that they would negotiate with the supervisor on how to distribute financial resources for future company-related research. They were to decide how many units (value: $€ 100.000$ each), from a pool of 100 units, they would offer to the supervisor and how many they would keep for themselves. The contingencies of this task were made clear to participants. If the supervisor accepted their offer, both would benefit from it as stated. However, if the supervisor rejected the offer, neither would benefit from it. Next, participants were asked how many units (ranging from 0-100) they offered the supervisor. Lower offers reflected more retaliatory (i.e., antisocial) behavior.

\section{Results and Discussion}

We conducted regression analyses with the main effects in Step 1 (regulatory focus, procedural fairness) and the interaction term in Step 2 (regulatory focus x procedural fairness). In order to reduce collinearity, we centered scores on regulatory focus and effect-coded $(-1,1)$ procedural fairness (Cohen, Cohen, West, \& Aiken, 2003). The interaction term was based on the product of the centered regulatory focus scores and the effect-coded procedural fairness. There was no evidence of collinearity: tolerance $>.99$; variance inflation factor $=1$. 
Manipulation checks. A hierarchical regression analysis on perceived accuracy revealed that the equation accounted for a significant amount of variance $(R=.91), F(4,66)=35.89, p<$ .001 . This analysis yielded only a procedural fairness main effect, $\beta=.78, p<.001$, partial $r=$ $.81,95 \% C I[1.25 ; 1.78]:$ Participants in the accurate condition $(M=5.23, S D=1.19)$ regarded the procedure as more accurate than those in the inaccurate condition $(M=2.15, S D=1.23)$.

A hierarchical regression analysis on fairness perceptions also revealed that the equation accounted for a significant amount of variance $(R=.87), F(4,66)=22.26, p<.001$. This analysis yielded only a procedural fairness main effect, $\beta=.74, p<.001$, partial $r=.75,95 \%$ $C I[1.07 ; 1.66]$. Participants in the accurate condition regarded the scenario as fairer $(M=5.00$, $S D=1.28)$ than those in the inaccurate condition $(M=2.07, S D=1.23)$. The procedural fairness manipulation was effective.

Retaliation. The results of the hierarchical regression analysis on antisocial offers are displayed in Table 1 . This regression equation accounted for a significant amount of variance $(R$ $=.57), F(4,66)=7.76, p<.001$. Antisocial offers was predicted by regulatory focus, $\beta=-.23, p$ $<.05$, partial $r=-.25,95 \% C I[-7.57 ;-.29]$. Promotion-focus participants made lower offers than prevention-focus participants. In contrast to Study 1, there was no procedural fairness main effect, $\beta=.11, p>.30$, partial $r=.13$.

More important to our hypothesis, however, was that the interaction significantly predicted antisocial offers, $\beta=.24, p<.05$, partial $r=.28,95 \% C I[.66 ; 7.69]$. We proceeded with computing the relation between procedural fairness and antisocial offers at a high (1 SD below the mean) and a low (1 SD above the mean) level of regulatory focus, respectively signifying promotion and prevention focus (Figure 2). Simple slope analyses revealed that the relation between retaliation and unfair treatment was significant among promotion-focus, $\beta=$ $.37, p<.05$, partial $r=.29,95 \% C I[1.31 ; 12.55]$, but not among prevention-focus participants, $\beta$ $=-.13, p>.36$, partial $r=-.11$. Promotion-focus (compared to prevention-focus) participants 
were more likely to behave in a retaliatory manner. Alternatively, regulatory focus was related to antisocial offers in the unfair, $\beta=-.38, p=.01$, partial $r=-.43,95 \% C I[-13.38 ;-1.90]$, but not in the fair procedural fairness condition, $\beta=.03, p>.87$, partial $r=.03$. Retaliation was predicted by regulatory focus in the unfair treatment condition.

Summary. Study 2 conceptually replicated the theoretically-relevant findings of the first study, using a different measure of retaliation (i.e., an UBG-offer) and with dispositional (rather than momentarily-activated) differences in regulatory focus. In particular, participants with a promotion (vis a vis prevention) focus were more retaliatory (i.e., made more antisocial offers) to a procedurally unfair (as opposed to fair) authority. Taken together, the results of the first two studies converge in supporting the hypothesis that regulatory focus moderates retaliation to unfair treatment in such a way that this effect emerges more frequently among persons with a dispositional or momentarily-activated promotion focus.

Study 3

Why is retaliation to unfair treatment localized in promotion-focus persons? What drives such persons toward retaliatory responses? Promotion-focus strategies vary along with independence and autonomy of the goal pursuit process (Lee et al., 2000; Meyer et al., 2004; Van-Dijk \& Kluger, 2004). Moreover, relative to their prevention-focus counterparts, promotionfocus persons appear to be influenced behaviorally by personal interest (Galinsky et al., 2005), have self-esteem concerns accessible in their minds (Leonardelli et al., 2007), and report lower self-esteem following failure (Moretti \& Higgins, 1990). Is, then, promotion focus associated with a chronically accessible individual self (Sedikides \& Brewer, 2001a)? Does situationallyactivated promotion focus heighten the accessibility of the individual self? The objectives of Study 3 were to address these questions.

We first examined the relation between dispositional regulatory focus and an indicator of chronic individual-self accessibility, private self-consciousness (PrSC; Fenigstein, Scheier, \& 
Buss, 1976). In particular, PrSC reflects awareness of inner aspects of the self, such as beliefs, values, and moods. People high as opposed to low in PrSC are more likely to value individual over collective identity (Cheek \& Briggs, 1982). We hypothesized that promotion focus is associated with chronic individual-self accessibility. A pilot study $(n=76)$ confirmed this hypothesis. Promotion focus and PrSC were positively correlated, $r=.31, p<.01$, whereas prevention focus and PrSC were uncorrelated, $r=.07, p>.57$.

We wanted to provide a more compelling assessment of the association between promotion focus and individual-self accessibility. Thus, we manipulated regulatory focus (in a different way than Study 1) and measured individual-self accessibility. We induced regulatory focus with a visual technique developed by Friedman and Förster (2001). These researchers implemented an instruction-free manipulation in the form of a simple maze. In one version of the maze, participants attempt to find the way for a cartoon mouse (trapped inside the maze) toward a piece of cheese lying outside the maze. Completion of this version corresponds to the promotion-focus strategy of seeking nurturance. In the other version of the maze, participants also attempt to find the way for the cartoon mouse, but now there is an owl flying above the maze, presumably ready to fly down and capture the mouse. Completion of this version corresponds to the prevention-focus strategy of seeking security.

Participants completed the maze and subsequently engaged in a 3-minute open-ended thought-listing task, thought to assess the momentary accessibility of individual self (Cacioppo \& Petty, 1982; Gaertner et al., 1999; Greenberg \& Pyszczynski, 1985). We were interested, in particular, in the relative frequency of first-person pronouns. We hypothesized that the induction of regulatory focus would influence the accessibility of individual self: participants in the promotion-focus condition would list more first-person pronouns than participants in the prevention-focus condition.

\section{Method}


Participants and design. Forty seven persons (31 females, 16 males; $\mathrm{M}_{\mathrm{age}}=22.50, S D=$ 6.36) were paid $€ 7$ (\$10) each for participation. We used a one-factor design: regulatory focus (promotion vs. prevention).

Procedure. Participants were seated in separate cubicles, containing a table, a chair, and a pencil. First, they received either the cheese (promotion-focus) or owl (prevention-focus) version of the maze. All participants completed this task successfully. Subsequently, they received the following instructions for an ostensibly unrelated thought-listing procedure: "Write down everything that crosses your mind right now. There is no need to reflect upon your writings; anything is good, as long as you write with full sentences. You have three minutes for this task." An independent judge counted the total number of first-person pronouns used. We proceeded to create relative scores for each participant by dividing the amount of first-person pronouns by the total amount of words generated. We took the relative score for first-person pronouns as an index of personal concerns. Finally, as a manipulation check, we asked participants to recall and describe the maze drawings.

\section{Results and Discussion}

Five participants did not recall successfully the content of the maze drawings, thus casting doubt on whether they processed accurately the nurturance- or security-related cues. We excluded these participants from further analyses.

Thought-listing. We conducted a one-way ANOVA on the amount of first-person pronouns listed, with regulatory focus as the independent variable. As hypothesized, participants generated significantly more first-person pronouns after completing the cheese maze $(M=.12$, $S D=.03)$ than the owl maze $(M=.07, S D=.03), F(1,39)=34.38, p<.001, r=.69,95 \% C I[-$ $.07 ;-.03]$.

Summary. Promotion focus reflects individual-self accessibility. A pilot study indicated that dispositional promotion focus is positively associated with chronic individual-self- 
accessibility, operationalized in terms of PrSC. Moreover, an experiment demonstrated that temporarily-induced promotion focus led to higher individual-self accessibility, operationalized in terms of first-person pronouns.

\section{Study 4}

What are the implications of the association between promotion focus and individual self for retaliation? We have shown that promotion focus covaries with, or heightens the accessibility of, the individual self. Might it be possible, then, that the accessibility of the individual self is a reason why promotion-focus participants respond retaliatorily to unfair treatment? We tested this idea by manipulating individual-self accessibility in both promotion-focus and prevention-focus participants.

Particularly intriguing would be the behavior of prevention-focus participants. How would they be affected by the manipulation of individual-self accessibility? These persons respond to unfair treatment in a relatively non-retaliatory manner. However, activation of the individual self may transform their behavior. There is evidence that activation of the self fosters opportunistic responding (Gaertner et al., 2008; Miedema et al., 2006; Skitka, 2003; Stapel \& Van der Zee, 2006). If so, prevention-focus participants would become less inhibited in defending themselves and might respond to unfairness as retaliatorily as their promotion-focus counterparts. (We assume that activation of the individual self in promotion-focus participants would be inconsequential—i.e., a ceiling effect). We will refer to this possibility as the transformation hypothesis.

Alternatively, activation of the individual self could simply augment the dominant behavioral tendencies of both prevention-focus and promotion-focus persons. There is evidence that, when the self is activated, behavior becomes more consistent with values that are internalized or central (Scheier, Buss, \& Buss, 1978; Utz, 2004; Verplanken \& Holland, 2002). If so, promotion-focus participants would behave even more retaliatorily, and prevention-focus 
persons even more non-retariatorily, to unfair treatment. We will refer to this possibility as the amplification hypothesis.

In Study 4, we carried out a comparative test of the transformation and amplification hypotheses. We assessed regulatory focus, rendered the individual self accessible, and recorded retaliation. To simplify our design, and given the findings of Studies 1 and 2, we only used an unfair procedure condition.

\section{Method}

Participants and design. Seventy eight persons (49 females, 29 males; $\mathrm{M}_{\mathrm{age}}=20.12, S D=$ 2.82) participated voluntarily, receiving a snack at the end of the study. Following the assessment of regulatory focus, participants were assigned to one of the two individual-self condition: high accessibility (i.e., I-prime), low accessibility (i.e., neutral-prime).

Material and procedure. Participants were seated at different tables and given a stimulus booklet ostensibly containing several unrelated studies. Participants began by completing the regulatory focus scale $(M s=5.05$ vs. $3.55 ; S D s=.70 \mathrm{vs} . .83$, for the promotion and prevention focus subscales respectively). The two subscales were uncorrelated $(r=.12, p>.30)$. We proceeded to subtract the prevention-focus $(\alpha=.74)$ from the promotion-focus $(\alpha=.75)$ subscale. The resulting scale was correlated both with the promotion-focus $(r=.59, p<.001)$ and prevention-focus $(r=-.73, p<.001)$ subscales.

Next, participants engaged in a writing task, which in actuality was the individual-self accessibility manipulation. They wrote a short paragraph on an assigned topic. In the high individual-self accessibility (I-prime) condition, they wrote a story about themselves. They were instructed to record "how they behave and feel at this university," while including at least one of ' $I$ ', ' $m e$ ', ' $m y$ ', or ' mine' in every sentence. We borrowed this technique from Fenigstein and Levine (1984; see also: Brewer \& Gardner, 1996; Stapel \& Van der Zee, 2006). In the low individual-self accessibility (neutral-prime) condition, participants wrote a story about the 
characteristics of a chair. We checked the effectiveness of this manipulation by computing the number of first-person pronouns in each condition.

Subsequently, participants received the same scenario as in Study 2. In brief, they imagined that, as employees in a large company, they completed a 9-test screening task that would determine professional advancement. All participants were informed that the supervisor used an inaccurate procedure (i.e., grading only 1 of 9 tests). We checked the effectiveness of the manipulation with the question "How accurate was the decision-making process?" $(1=$ not at all, 7 = very much so $)$ and assessed retaliation with an UBG, also as in Study 2.

\section{Results and Discussion}

We conducted regression analyses with the main effects in Step 1 (individual-self accessibility and regulatory focus), and the interaction term in Step 2 (individual-self accessibility x regulatory focus). In order to reduce collinearity, we effect-coded individual-self accessibility $(-1,1)$ and centered participants' scores on the regulatory focus scale. The interaction term was based on the product of the effect-coded manipulation and the centered regulatory focus scores. There was no evidence for collinearity: tolerance $>.99$; variance inflation factor $=1$.

Manipulation check. We submitted the first-person pronouns to a hierarchical regression analysis. The regression equation accounted for a significant amount of variance $(R=.92), F(4$, $73)=86.85, p<.001$. Moreover, the number of first-person pronouns was predicted significantly by the individual-self accessibility main effect, $\beta=.92, p<.001$, partial $r=.92,95 \% C I[.08$; .10]. As intended, participants in the I-prime condition used a higher number of first-person pronouns $(M=.18, S D=.05)$ than participants in the neutral-prime condition $(M=.01, S D=$ $.02)$. Neither the regulatory focus main effect nor the interaction term predicted use of firstperson pronouns (both $p \mathrm{~s}>.14$, partial $r \mathrm{~s}>-.18$ ). The manipulation was effective. In general, participants considered the decision-making process as relatively inaccurate $(M=1.93, S D=$ 
1.06). A one-sample t-test revealed that the mean differed significantly from the mid-point (i.e., 4) of the scale, $t(77)=-17.87, p<001$.

Retaliation. The regression equation accounted for a significant amount of variance $(R=$ $.41), F(4,73)=3.13, p<.01$. As shown in Table 2 , the interaction was significant, $\beta=.26, p<$ .05 , partial $r=.27,95 \% C I[.45 ; 6.37]$. We computed the relation between regulatory focus and antisocial offers at both levels of individual-self accessibility (Figure 3). In the low level (i.e., neutral-prime condition), regulatory focus significantly predicted retaliation, $\beta=-.46, p<.01$, partial $r=-.46$, such that promotion focus was related to more antisocial offers than prevention focus. However, in the high level (i.e., I-prime condition), regulatory focus did not predict antisocial offers, $\beta=.08, p>.66$, partial $r=.08$. As such, offers did not vary as a function of regulatory focus. Alternatively, among prevention-focus participants, individual-self accessibility influenced antisocial offers, $\beta=-.45, p<.01$, partial $r=-.33$, such that high (compared to low) accessibility led to more antisocial offers. Among promotion-focus participants, however, individual-self accessibility had no influence on antisocial offers, $\beta=.06, p>.69$, partial $r=.05$.

Summary. The findings were consistent with the transformation hypothesis at the expense of the amplification hypothesis. When the temporary accessibility of the individual self was low, prevention-focus participants behaved less retaliatorily than promotion-focus participants toward an unfair authority. This pattern replicates the unfair procedure condition findings of Studies 1 and 2. On the other hand, when the temporary accessibility of the individual self was high, prevention-focus participants were as retaliatory as promotion-focus participants. This pattern is novel and intriguing. It is also preliminary and in need of replication.

\section{Study 5}

Study 5 attempted to replicate the Study 4 findings with temporarily-induced regulatory focus, a different manipulation of individual-self accessibility, and in a social interaction setting. Participants first engaged in a screening task for their assignment to a group role (as in Study 1). 
Also, participants were primed not only with promotion or prevention focus referring to their lives in general (as in Study 1; Idson et al., 2000) but also with promotion or prevention focus referring to the group problem-solving task in which they expected to engage (Galinsky et al., 2005).

Study 5 also used a different manipulation of individual-self accessibility, namely high versus low uniqueness or authenticity. Specifically, participants received performance feedback that either emphasized their uniqueness/authenticity or not. Next, participants learned that the authority enacted an unfair (i.e., inaccurate) decision-making procedure. We assessed behavior with an UBG, as in Studies 2 and 4.

In the low individual-self accessibility (i.e., no feedback) condition, we expected to replicate the unfair treatment findings previously observed in Studies 1, 2 and 4: Promotionfocus participants would be more retaliatory than prevention-focus participants. However, in the high individual-self accessibility (i.e., uniqueness/authenticity feedback) condition, we expected for this effect to be cancelled out, as in Study 4: Promotion- and prevention-focus participants would not differ in degree of retaliatory behavior.

\section{Method}

Participants and design. Seventy eight persons (58 females, 20 males; $\mathrm{M}_{\mathrm{age}}=20.34, \mathrm{SD}$ $=2.49)$ were paid $€ 7(\$ 10)$ for participation. As in Study 4, all participants received unfair (i.e., inaccurate) treatment. We used a $2 \times 2$ between-subjects design. The first factor was regulatory focus (promotion vs. prevention). The second factor was individual-self accessibility, split into high (uniqueness/authenticity feedback) and low (no feedback).

Experimental procedure. Participants completed a 3-page booklet, cast as the SelfInventory Scale (SIS). The SIS was said to be a standardized personality test that generated different personality profiles depending upon one's percentile scores. Participants were told that they would receive feedback about their profile, but it was not specified when this would occur. 
Then, the actual experiment started. The experimental procedure was very similar to that of Study 1. Participants completed the screening task and proceeded to work on the 5-test battery that would ostensibly help Manager A assign them to a group-role. Upon completion, participants contacted the experimenter. He entered the cubicle, collected their test results, announced that he would hand them over to Manager A, and gave participants another task. This was the manipulation of regulatory focus, in which half of the participants listed promotion-focus goals and the other half listed prevention-focus goals. Participants completed this task twice: once for a current promotion/prevention goal in their lives (ex-context goal; Idson et al., 2000) and once for a promotion/prevention goal about the upcoming group task (in-context goal; Galinsky et al., 2005). When finished, participants again contacted the experimenter.

The individual-self accessibility manipulation followed. Participants in the high individual-self accessibility condition received a standard form with a handwritten indication of the percentile that corresponded to their scores on the SIS and also an accompanying profile description feedback that they were allowed to keep. Each participant was informed that she or he had scored very highly (i.e., $95^{\text {th }}$ percentile) compared to the reference sample. The profile feedback read as follows:

Few others (only $5 \%$ ) have such a unique and specific way of handling things as you do. You are always true to yourself and you are never guided by others. Whether you're dealing with family, friends or business relationships, you always maintain your true self, which generally makes you feel good. Also, as a unique person, you know yourself remarkably well. It must be very important to you to always keep in mind your own goals. Otherwise, you risk losing yourself in life.

Participants in the low individual-self accessibility condition were given no self-relevant feedback. 
Next, as in Study 1, participants received handwritten feedback in an envelope from Manager A. All participants learned that the manager used an inaccurate procedure (i.e., grading only 1 of 5 tests) to allocate them to group-roles. Before leaving the cubicle to commence the group-decision task, participants responded to the perceived accuracy ("To what extent do you think Manager A will make the decision in an accurate manner?") and perceived fairness ("To what extent does manager A treated you fairly?") manipulation checks $(1=$ not at all, $7=$ very much so). Finally, as in Studies 2 and 4, we recorded the UBG offers that participant made as a measure for retaliation.

\section{Results and Discussion}

Manipulation checks. As in Study 1, two judges independently coded goal-descriptions as either promotion or prevention focus. Both judges rated every goal-description and agreed on 90 $\%($ Kappa $=.79)$ of them. Disagreement was equally low for promotion $(10 \%)$ and preventionfocus $(10 \%)$ conditions. This indicates that participants followed the instructions, as intended. Disagreements between judges were resolved with discussion, and resolutions were included in the analyses.

Participants perceived the decision-making process as relatively inaccurate $(M=2.19, S D$ $=.93$ ). A one-sample t-test showed that the mean differed significantly from the scale mid-point (i.e., 4), $t(77)=-16.99, p<.001$. Also, participants perceived the decision-making process as relatively unfair $(M=3.40, S D=1.59)$. A one-sample t-test revealed that the mean was significantly different from the scale mid-point (i.e., 4), $t(77)=-3.35, p<.001$.

Retaliation. A 2 × 2 ANOVA revealed a main effect of individual self-accessibility, $F(1$, $73)=4.13, p=.05, r=.22,95 \% C I[-10.97 ; 6.82]:$ High than low individual self-accessibility resulted in more antisocial offers. More important to our hypothesis, this effect was qualified by a significant interaction, $F(1,73)=7.23, p<.01, r=.29,95 \% C I[4.40 ; 29.63]$ (Figure 4). Simple effects analyses yielded a significant regulatory focus effect in the low individual-self 
accessibility (i.e., no-feedback) condition, $F(1,73)=4.64, p<.05, r=.25$, such that promotionfocus participants $(M=44.52, S D=13.87)$ made more antisocial offers than prevention-focus participants $(M=53.74, S D=17.38)$. However, the regulatory focus effect was not significant in the high individual-self accessibility (i.e., uniqueness/authenticity feedback) condition, $F(1,73)$ $=2.76, p>.10, r=.19$, such that promotion-focus $(M=46.67, S D=10.98)$ and prevention-focus $(M=40.25, S D=14.28)$ participants did not differ in the extent to which their offers were antisocial.

Alternatively, in the prevention-focus condition, individual-self accessibility had a significant impact on behavior, $F(1,75)=11.07, p=.001, r=.36$, such that offers were more antisocial in the high $(M=40.25, S D=14.28)$ than low $(M=55.61, S D=15.87)$ individual-self accessibility condition. In the promotion-focus condition, however, individual-self accessibility had no impact on retaliation, $F(1,75)<1, p>.66, r=.05$, indicating that offers were equally antisocial in the high $(M=46.67, S D=10.98)$ and low $(M=44.52, S D=13.87)$ accessibility conditions.

Summary. The results of Study 5 replicated those of Study 4 in providing further evidence for the transformation hypothesis. When individual-self accessibility was low (i.e., no feedback), prevention-focus participants responded less retaliatorily to unfair treatment than their promotion-focus counterparts. However, when individual-self accessibility was high (i.e., uniqueness/assessment feedback), prevention-focus participants were as retaliatory toward an unfair authority as promotion-focus participants.

\section{General Discussion}

First, we will summarize the main objectives and findings of our research. Then, we will discuss the implications of our findings. These implications involve broad considerations for the literature, practical implications, possible limitations, and suggestions for future research. 
Although unfair treatment would be expected to lead to retaliation in group or organizational settings, the findings, when meta-analyzed, proved to be inconsistent (Colquitt et al., 2001). A call for moderators ensued (Colquitt et al., 2006). In this article, we responded to this call by addressing two issues: When unfair treatment results in retaliation, and why the recipients sometime pursue and other times inhibit retaliation.

When will unfair treatment result in retaliation? We addressed the "when" issue by exploring the moderational role of regulatory focus (Higgins, 1998) in Studies 1 and 2. Promotion focus reflects nurturance concerns (e.g., hopes, aspirations) and is associated with goal-pursuit strategies that are willful, approach-oriented, and direct. Prevention focus, on the other hand, reflects security concerns (e.g., duties, responsibilities) and is associated with goalpursuit strategies that are vigilant, avoidance-oriented, and deliberate. How would these regulatory foci and goal-pursuit strategies play out in a procedural (un)fairness setting?

Given evidence that promotion-focus is associated with neural correlates of retaliation (Amodio et al., 2004; Harmon-Jones \& Sigelman, 2001) and evidence that prevention-focus is associated with self-silencing, withdrawal, and inhibition of hostility in the anticipation of unfairness or rejection (Ayduk et al., 2003; Oyserman et al., 2007, Study 3), we hypothesized and found that promotion-focus (compared to prevention-focus) participants were more likely to retaliate against an authority who enacted unfair procedures. Moreover, we obtained this pattern across momentarily-induced (Study 1) and dispositional (Study 2) regulatory foci, and across different retaliatory responses (i.e., stealing in Study 1, UBG offers in Study 2).

Why do procedural unfairness recipients sometime pursue and other times inhibit retaliation? We addressed the "why" issue in Studies 3-5. When engaging in face-to-face negotiation, promotion-focus participants concentrate on their personal target prices (Galinsky et al., 2005). The self-esteem concerns of such participants are relatively accessible (Leonardelli et al., 2007) and their self-esteem reportedly drops in the case of failure (Moretti \& Higgins, 1990). 
It is likely, then, that promotion focus is associated with, or heightens the accessibility of, the individual self (Sedikides \& Brewer, 2001a). This type of self is characterized by enhancement or defense motivation (Sedikides \& Strube, 1997). Accessibility of the individual self is linked with construal of social interactions as a zero-sum game and with competitive behavior (Stapel \& Van der Zee, 2006), a pattern that has been observed in procedural (un)fairness settings (Miedema et al., 2006; Skitka, 2003). In summary, (a) promotion focus might be associated with heightened accessibility of the individual self, which, in turn, (b) would influence retaliatory responding. If so, it would be interesting to explore how accessibility of the individual self influences the behavior of prevention-focus participants.

Study 3 examined the idea that promotion focus is associated with heightened accessibility of the individual self. A pilot study showed that promotion focus is positively related to private self-consciousness, an indicator of chronic individual-self accessibility. Prevention-focus was uncorrelated with private self-consciousness. More importantly, an experiment provided evidence that induction of promotion (but not prevention) focus leads to higher individual-self accessibility, as indicated by the use of first-person pronouns.

Studies 4 and 5 examined the idea that heightened individual self-accessibility influences retaliatory responding by exploring the influence of individual-self accessibility on retaliation toward unfair treatment. In particular, these studies tested two competing hypotheses. According to the transformation hypothesis, high (vs. low) individual-self accessibility would transform the behavior of prevention-focus participants in such a way that they would behave as retaliatorily as promotion-focus participants. According to the amplification hypothesis, high (vs. low) individual-self accessibility would reinforce dominant responses in such a way that preventionfocus participants would behave less retaliatorily, and promotion-focus participants would behave more retaliatorily. The results were consistent with the transformation hypothesis. Prevention-focus participants were as retaliatory as promotion-focus participants under 
conditions of high individual-self accessibility. The results were replicated across temporarilyinduced (Study 5) and dispositional (Study 4) regulatory foci, and across individual selfaccessibility manipulations (i.e., self-activation in Study 4, uniqueness/authenticity feedback in Study 5).

\section{Implications}

Broad considerations. Our research falls in the general tradition of emphasizing the role of self and identity in the justice process (Sedikides, Hart, \& De Cremer, in press). This tradition is reflected in such theoretical models as the relational model of authority (Tyler \& Lind, 1992), the group engagement model (Tyler \& Blader, 2000), and the self-based model of cooperation (De Cremer \& Tyler, 2005). In particular, our research is more compatible with theoretical and empirical accounts that view procedural unfairness as a threat to the self (Miedema et al., 2006; Skitka, 2003; Skitka \& Bravo, 2005). Our research expanded this knowledge base by identifying an important moderator: regulatory focus. Promotion-focus persons respond more directly or retaliatorily to procedural unfairness than prevention-focus persons. Furthermore, our research pinpointed the locus of such behavior: self-activation. In fact, when the individual self of prevention-focus persons was activated, they responded as retaliatorily to the enactor of the unfair treatment as promotion-focus persons did.

These findings have implications for research on both procedural fairness and regulatory focus. With respect to the procedural fairness literature, our research, first of all, stresses the importance of studying the psychology of unfairness along with the psychology of fairness (De Cremer \& Ruiter, 2003; De Cremer \& Sedikides, 2005; Van Prooijen et al., 2006; Van Prooijen, Van den Bos, Lind, \& Wilke, 2006). Research to date has mainly been involved with understanding how procedural fairness influences a variety of positive reactions or responses such as self-esteem, satisfaction, cooperation, and legitimacy. It is becoming increasingly evident, however, that many effects are driven by the unfairness rather than fairness component. 
Moreover, most of these effects have been documented on affective, cognitive, or attitudinal measures, but less so on behavioral ones: The effects of procedural unfairness on behavior are rather poorly understood. An example is the effect of unfairness on retaliation (Bembenek et al., 2007; Colquitt et al., 2001; Posthuma et al., 2007), which has produced inconsistent findings. Our research has helped clarifying this effect by addressing the role of regulatory focus.

Relatedly, our findings illustrate the usefulness of the regulatory focus construct in the context of social interactions. As noted by Galinsky et al. (2005), this is an under-investigated topic. Procedural fairness settings constitute such a promising social interaction paradigm within which to explore regulatory focus effects. In addition, our findings inform the specifics of promotion-focus in social interactions. Such a focus is more strongly associated with individualself concerns than a prevention-focus is. This difference offers an explanation for why promotion-focus persons are more likely to retaliate in the face of unfair treatment.

Practical implications. Organizations often adopt an economic perspective in which virtually only outcomes matter, implying that the process through which outcome allocation is decided (i.e., procedural fairness) does not make a difference (Korsgaard \& Sapienza, 2002). After all, if employees were bothered by unfair procedures, they should react to them, something that often does not happen, as employees keep quiet. Our findings and the regulatory focus literature suggest that employee acquiescence is a function of disposition and situation. First, prevention-focus employees (or group members) would be less likely to react to unfairness than promotion-focus employees. Second, organizational environments that foster safety, security, and conformity are less likely to encourage and evoke reactions to unfairness than organizational environments that foster comfort, accomplishment, and aspiration (cf. Werth \& Förster, 2007). Good management, then, would aim both to identify employees with different regulatory foci and also change accordingly the organizational environment. 
We have referred to non-retaliatory behavior as constructive, and to retaliatory behavior as destructive. As implied by the above paragraph, the terms constructive and destructive can often resume alternate meaning, depending on organizational environment and organizational (or individual) goals. Retaliation, for example, could sometimes be interpreted as a call to institute changes in organizational or leadership practices (Bies \& Tripp, 1998; Tripp \& Bies, 1997).

Limitations and suggestions for future research. Prior research has suggested that promotion-focus is associated with more immediate, more active, and less deliberative responding than prevention-focus (Crowe \& Higgins, 1997; Van-Dijk \& Kluger, 2004). Does this proclivity generalize both to negative (e.g., retaliatory) and positive (e.g., prosocial) responding? For theoretically-relevant reasons, we focused exclusively on negative responding in our studies. Future research would do well to assess positive responding (e.g., cooperation, reconciliation, forgiveness) as well (Aquino et al., 2001, 2006). Such research would rely on the assumption that both promotion- and prevention-focus can predict active coping in interpersonal situations (Ayduk et al., 2003; Grant \& Higgins, 2003). Indeed, promotion-focus persons need not necessarily be considered as across-the-board more active or reactive problem-solvers than their prevention-focus counterparts. Instead, the specific characteristics of the situation and the problem-solving activity may interactively determine whether promotion- versus preventionfocus persons cope more or less actively with social feedback.

On a related note, our research assessed retaliatory behavior in a decision-making paradigm. Although many situations in groups and organizations can be characterized by a conflict of interest, as operationalized by the UBG, the ecological validity of the UBG may not be particularly high. Despite the fact that the allocation decisions respondents make in an UBG are usually referred to as behavioral responses (Boles, Croson, \& Murnighan, 2000), these decisions reflect a somewhat narrow focus on behavior. This reflection may be one explanation for the relatively weak effect sizes in our studies. Future research would do need to replicate the 
present findings in real-life contexts, such as organizational or household conflicts, in which a wider range of behaviors can be assessed.

Our research showed that, all else being equal, promotion-focus persons are more likely than prevention-focus ones to retaliate against perceived unfair treatment. However, our research also identified a condition under which those with a prevention focus retaliate, that is, when the individual self was accessible. A profitable direction for future research would be to explore additional conditions under which prevention-focus persons are likely to take retaliatory action. For example, rather than directly responding in a negative way, prevention-focus persons may show indirect retaliation such as gossiping, passively undermining the enacting authority, or omitting to perform positive acts.. This line of reasoning is in accordance with social cognitive theories of aggression, which posit that displaced or indirect aggression emerges when people experience a lack of opportunities for direct action or when they fear counter-retaliation from the unfairness source (Anderson \& Bushman, 2002; Bushman, Bonacci, Pedersen, Vazquez, \& Miller, 2005). Might it be, then, that prevention-focus persons manifest indirect retaliation when the offender is relatively powerless or when circumstances allow for covert action? Research on power-asymmetry, for example, has shown that downward retaliation (i.e., when the offender is less powerful) is greater than upward retaliation (i.e., when the offender is more powerful), but only under circumstances that allow for covert action (Kim, Smith, \& Brigham, 1998). Indirect forms of retaliation may also be influenced by a group context such that prevention-focus persons may be likely to engage in retaliation in an effort to protect the interests of their ingroup when the unfairly-enacting authority belongs to an antagonistic outgroup (Sassenberg \& Hansen, 2007). These suggestions fit within a rational choice perspective, in which retaliation is more likely when cost-expectancies are low or when it represents a means to avoid losses. Retaliation, then, can be seen as resulting from a hedonistic calculus - an idea originating from classical views on criminology (Beccaria, 1764/1986; Matsueda, Kreager, \& Huizinga, 2006). 
Finally, future research would benefit from an attempt to reconcile empirical inconsistencies pertaining to the role of regulatory focus in intra-individual (e.g., taskperformance) versus inter-individual settings (e.g., procedure-based feedback). Particularly relevant to this point is recent research suggesting that regulatory focus effects may reveal contrasting patterns in situations in which people anticipate versus react toward negative feedback (Friedman \& Förster, 2005, Study 3). Relying on left versus right hemispheric activation patterns, this research shows that motivational mechanisms operate differently when people perform a task in order to avoid (approach) negative (positive) feedback in intraindividual settings than when people cope (react) as recipients of negative (positive) feedback in inter-individual settings. Other research in the same tradition has demonstrated that, when actual feedback is given, a promotion-focus is associated with greater left hemispheric activation, which in turn is associated with retaliatory responding toward interpersonal provocation (Amodio et al., 2004; Harmon-Jones \& Sigelman, 2001) — a pattern consistent with our findings. In Closing

The current investigation establishes self-regulatory focus as a moderator of retaliation in response to perceived unfairness. It is promotion-focus that is associated with, or leads to, retaliation. Furthermore, it is chronic or temporary accessibility of the individual self that drives retaliatory responding. We hope that our investigation will spark additional forays into the relation between self-regulation, procedure-based feedback, and behavior. 


\section{References}

Aiken, L. S., \& West, S. G. (1991). Multiple regression: Testing and interpreting interactions. Newbury Park, CA: Sage

Amodio, D. M., Shah, J.Y., Sigelman, J., Brazy, P. C., \& Harmon-Jones, E. (2004). Implicit regulatory focus associated with asymmetrical frontal cortical activity. Journal of Experimental Social Psychology, 40, 225-232.

Anderson, C. A., \& Bushman, B. A. (2002). Human Aggression. Annual Review of Social Psychology, 53, 21-57.

Aquino, K., Tripp, T. M., \& Bies, R. J. (2001). How employees respond to personal offense: The effects of blame attribution, victim status, and offender status on revenge and reconciliation in the workplace. Journal of Applied Psychology, 86, 52-59.

Aquino, K., Tripp, T. M., \& Bies, R. J. (2006). Getting even or moving on?: Power, procedural justice, and types of offense as predictors of revenge, forgiveness, reconciliation, and avoidance in organizations. Journal of Applied Psychology, 91, 653-668.

Ayduk, O., May, D., Downey, G., \& Higgins, E. T. (2003). Tactical differences in coping with rejection sensitivity: The role of prevention pride. Personality and Social Psychology Bulletin, 29, 435-448.

Barclay, L. J., Skarlicki, D. P., \& Pugh, S. D. (2005). Exploring the role of emotions in injustice perceptions and retaliation. Journal of Applied Psychology, 90, 629-643.

Beccaria, C. (1764/1986). On crimes and punishments. Indianapolis: Hackett Publishing.

Bembenek, A. F., Beike, D. R., \& Schroeder, D. A. (2007). Justice violations, emotional reactions, and justice-seeking responses. In D. De Cremer (Ed.), Advances in the Psychology of Justice and Emotions (pp. 15-36). Greenwich, CT: Information Age Publishing. 
Bettencourt, B. A., \& Miller, N. (1996). Gender differences in aggression as a function of provocation: A meta-analysis. Psychological Bulletin, 119, 422-447.

Bies, R. J., \& Tripp, T. M. (1996). Beyond distrust: “Getting even” and the need for revenge. In R. Kramer \& T. R. Tyler (Eds.), Trust in organizations (pp. 246-260). Thousand Oaks, CA: Sage.

Bies, R. J., \& Tripp, T. M. (1998). Revenge in organizations: The good, the bad, and the ugly. In R. Griffin, A. O’Leary-Kelly, \& J. Collins (Eds.), 165-1 83. Dysfunctional behavior in organizations: Non-violent dysfunctional behavior (pp. 49-67). Stamford, CT: JA1.

Bies, R. J., Tripp, T. M., \& Kramer, R. M. (1997). At the breaking point: Cognitive and social dynamics of revenge in organizations. In R. A. Giacalone \& J. Greenberg (Eds.), Antisocial behavior in organizations (pp. 18-36). Thousand Oaks, CA: Sage.

Blader, S. L, Chang, C. C., \& Tyler, T. R. (2001). Procedural justice and retaliation in organizations: Comparing cross-nationally the importance of fair group processes. The International Journal of Conflict Management, 12, 295-311.

Boles, T. L., Croson, R. T. A., \& Murnighan, J. K. (2000). Deception and retribution in repeated ultimatum bargaining. Organizational Behavior and Human Decision Processes, 83, $235-259$.

Brewer, M. B., \& Gardner, W. (1996). Who is this "we"?: Levels of collective identity and selfrepresentations. Journal of Personality and Social Psychology, 71, 83-93.

Bushman, B. J., Bonacci, A. M., Pedersen, W. C., Vazquez, E. A., \& Miller, N. (2005). Chewing on $t$ can chew you up: Effects of rumination on triggered displaced aggression. Journal of Personality and Social Psychology, 88, 969-983.

Cacioppo, J. T., \& Petty, R. E. (1982). The need for cognition. Journal of Personality and Social Psychology, 42, 116-131. 
Camacho, C. J., Higgins, E. T. \& Luger, L. (2003). Moral value transfer from regulatory fit: What feels right is right and what feels wrong is wrong. Journal of Personality and Social Psychology, 84, 498-510.

Cheek, J. M., \& Briggs, S. R. (1982). Self-consciousness and aspects of identity. Journal of Research in Personality, 16, 401-408.

Cohen, J., Cohen, P., West, S., \& Aiken, L. (2003). Applied multiple regression / correlation analysis for the behavioral sciences (3rd Ed.). Hillsdale, NJ: Lawrence Erlbaum Associates.

Colquitt, J. A., Conlon, D. E., Wesson, M. J., Porter, C. O., \& Ng, K. Y. (2001). Justice at the Millenium: A meta-analytic review of 25 years of organizational justice research. Journal of Applied Psychology, 86, 425-445.

Colquitt, J. A., Scott, B. A., Judge, T. A., \& Shaw, J. C. (2006). Justice and Personality. Using integrative theories to derive moderators of justice effects. OrganizationalBehavior and Human Decision Processes, 100, 110-127.

Crowe, E., \& Higgins, E. T. (1997). Regulatory focus and strategic inclinations: Promotion and prevention in decision-making. Organizational Behavior and Human Decision Processes, 69, 117-132.

De Cremer, D. (2004). The influence of accuracy as a function of leader's bias: The role of trustworthiness in the psychology of procedural justice. Personality and Social Psychology Bulletin, 30, 293-304.

De Cremer, D. (2007). Advances in the psychology of justice and affect. Greenwich, CT: Information Age Publishing.

De Cremer, D., \& Blader, S. (2006). Why do people care about procedural fairness? The importance of belongingness in responding and attending to procedures. European Journal of Social Psychology, 36, 211-228. 
De Cremer, D., \& Ruiter, R. A. C (2003). Emotional reactions toward procedural fairness as a function of negative information. Journal of Social Psychology, 143, 793-795.

De Cremer, D., \& Sedikides, C. (2005). Self-uncertainty and responsiveness to procedural justice. Journal of Experimental Social Psychology, 41, 157-173.

De Cremer, D., \& Tyler, T. R. (2005). Managing group behavior: The interplay between procedural justice, sense of self, and cooperation. In M. Zanna (Ed.), Advances in experimental social psychology (Vol. 37, pp. 151-218). San Diego, CA: Academic Press.

De Cremer, D., \& Van Knippenberg, D. (2002). How do leaders promote cooperation? The effects of charisma and procedural fairness. Journal of Applied Psychology, 87, 858-866.

Epley, N., Caruso, E. M., \& Bazerman, M. H. (2006). When perspective-taking increases taking: Reactive egoism in social interaction. Journal of Personality and Social Psychology, 91, 873-889.

Fenigstein, A., \& Levine, M. P. (1984). Self-attention, concept-activation, and the causal self. Journal of Experimental Social Psychology, 20, 231-245.

Fenigstein, A., Scheier, M. F., \& Buss, A. H. (1975). Public and private self-consciousness: Assessment and theory. Journal of Consulting and Clinical Psychology, 43, 522-527.

Folger, R. (2001). Fairness as deonance. In S. W. Gilliland, D. D. Steiner, \& D. P. Skarlicki (Eds.), Research in social issues in management (Vol. 1, pp. 3-33). New York, NY: Information Age Publishers.

Friedman, R. S., \& Förster, J. (2001). The effects of promotion and prevention cues on creativity. Journal of Personality and Social Psychology, 81, 1001-1013.

Friedman, R. S., \& Förster, J. (2005). Effects of motivational cues on perceptual asymmetry: Implications for creativity and analytical problem solving. Journal of Personality and Social Psychology, 88, 263-275. 
Gaertner, L., \& Sedikides, C. (2005). A hierarchy within: On the motivational and emotional primacy of the individual self. In M. D. Alicke, D. A. Dunning, \& J. I. Krueger (Eds.), The self in social judgment (pp. 213-239). New York, NY: Psychology Press.

Gaertner, L., Sedikides, C., \& Graetz, K. (1999). In search of self-definition: Motivational primacy of the individual self, motivational primacy of the collective self, or contextual primacy? Journal of Personality and Social Psychology, 76, 5-18.

Gaertner, L., Sedikides, C., Luke, M. A., \& Iuzzini, J. (2008). Hierarchy among selves: An implication for relations with persons versus groups. In H. A. Wayment \& J. J. Bauer (Eds.), Transcending self-interest: Psychological explorations of the quiet ego (pp. 127135). Washington, DC: American Psychological Association.

Gaertner, L., Sedikides, C., Vevea, J., \& Iuzzini, J. (2002). The "I," the "We," and the "When:" A meta-analysis of motivational primacy in self-definition. Journal of Personality and Social Psychology, 83, 574-591.

Galinski, A. D., Leonardelli, G. J., Okhuysen, G. A., \& Mussweiler, T. (2005). Regulatory focus at the bargaining table: Promoting distributive and integrative success. Personality and Social Psychology Bulletin, 31, 1087-1098.

Giacalone, R. A., \& J. Greenberg (1997). Antisocial behavior in organizations. London, UK: Sage Publications.

Greenberg, J. (1993). Stealing in the name of justice: Informational and interpersonal moderators of theft reactions to underpayment inequity. Organizational Behavior and Human Decision Processes, 54, 81-103.

Greenberg, J. (1996). The quest for justice on the job. Thousand Oaks, CA: Sage Publications. Greenberg, J., Pyszczynski, T. (1985). Compensatory self-inflation: A response to the threat to self-regard of public failure. Journal of Personality and Social Psychology, 49, 273-280. 
Güth, W., Schmittberger, R., \& Schwarze, B. (1982). An experimental analysis of ultimatum games. Journal of Economic Behavior in Organizations, 3, 367-388.

Handgraaf, M. J. J., Van Dijk, E., \& De Cremer, D. (2003). Social utility in ultimatum bargaining. Social Justice Research, 16, 263-283.

Harmon-Jones, E., \& Allen, J. J. B. (1998). Anger and prefrontal brain activity: EEG asymmetry consistent with approach motivation despite negative affective valence. Journal of Personality and Social Psychology, 74, 1310-1316.

Harmon-Jones, E., \& Sigelman, J. (2001). State anger and prefrontal brain activity: Evidence that insult-related relative left-prefrontal activation is associated with experienced anger and aggression. Journal of Personality and Social Psychology, 80, 797-803.

Higgins, E. T. (1997). Beyond pleasure and pain. American Psychologist, 52, 1280-1300.

Higgins, E. T. (1998). Promotion and prevention: Regulatory focus as a motivational principle. In M. P. Zanna (Ed.), Advances in experimental social psychology (Vol. 30, pp. 1-46). New York: Academic Press.

Higgins, E. T., Friedman, R. S., Harlow, R. E., Idson, L. C., Ayduk, O. N., \& Taylor, A. (2001). Achievement orientation from subjective histories of success: promotion pride versus prevention pride. European Journal of Social Psychology, 31, 3-23.

Idson, L. C., \& Higgins, E. T. (2000). How current feedback and chronic effectiveness influence motivation: everything to gain versus everything to lose. European Journal of Social Psychology, 30, 583-592.

Idson, L. C., Liberman, N., \& Higgins, E. T. (2000). Distinguishing gains from non-losses and losses from non-gains: A regulatory focus perspective on hedonic intensity. Journal of Experimental Social Psychology, 36, 252-274. 
Kim, S. H., Smith, R. H., \& Brigham, N. L. (1998). Effects of power imbalance and the presence of third parties on reactions to harm: Upward and downward revenge. Personality and Social Psychology Bulletin, 24, 353-361.

Koper, G., van Knippenberg, D., Bouhuijs, F., Vermunt, R., \& Wilke, H. (1993). Procedural fairness and self-esteem. European Journal of Social Psychology, 23, 313-325.

Korsgaard, M.A., \& Sapienza, H. J. (2002). Economic and non-economic mechanisms in interpersonal work relationships: Toward an integration of agency and procedural justice theories. In S. W. Gilligand, D. D, Steiner, \& D. P. Skarlicki (Eds.), Emerging perspectives on managing organizational justice (pp. 3-34). Greenwich, CT: Information Age Publishing.

Korsgaard, M.A., Schweiger, D. M., \& Sapienza, H. J. (1995). Building commitment, attachment, and trust in strategic decision-making teams: The role of procedural justice. Academy of Management Journal, 38, 60-84.

Lee, A.Y., Aaker, J. L., \& Gardner, W. L. (2000). The pleasures and pains of distinct selfconstruals: The role of interdependence in regulatory focus. Journal of Personality and Social Psychology, 78, 1222-1234.

Leonardelli, G. J., Lakin, J. L., \& Arkin, R. M. (2007). A regulatory focus model of selfevaluation. Journal of Experimental Social Psychology, 43, 1002-1009.

Lerner, M. (2002). Pursuing the justice motive. In M. Ross \& D. T. Miller (Eds.), The justice motive in everyday life (pp. 10-40). Cambridge: Cambridge University Press.

Leventhal, G. S. (1980). What should be done with equity theory?: New approaches to the fairness in social relationships. In K. Gergen, M. Greenberg, \& R. Willis (Eds.), Social exchange theory (pp. 27-55). New York: Plenum.

Lind, E. A., \& Tyler, T. R. (1988). The social psychology of procedural justice. New York, NY: Plenum Press. 
Lockwood, P., Jordan, C. H., \& Kunda, Z. (2002). Motivation by positive or negative role models: Regulatory focus determines who will best inspire us. Journal of Personality and Social Psychology, 83, 854-864.

Matsueda, R. L., Kreager, D. A., \& Huizinga, D. (2006). Deterring delinquents: A rational choice model of theft and violence. American Sociological Review, 71, 95-122.

Meyer, J. P., Becker, T. E., \& Vandenberghe, C. (2004). Employee commitment and motivation: A conceptual analysis and integrative model. Journal of Applied Psychology, 89, 9911007.

Miedema, J., Van den Bos, K., \& Vermunt, R. (2006). The influence of self-threats on fairness judgments and affective measures. Social Justice Research, 19, 228-253.

Mikula, G. (1986). The experience of injustice: Toward a better understanding of its phenomenology. In H. W. Bierhoff, R. L. Cohen, \& J. Greenberg (Eds.), Justice in social relations (pp. 103-123). New York, NY: Plenum.

Miller, D. T. (2001). Disrespect and the experience of injustice. Annual Review of Psychology, $52,527-553$.

Moretti, M. M., \& Higgins, E. T. (1990). Relating self-discrepancy to self-esteem: The contribution of discrepancy beyond actual-self ratings. Journal of Experimental Social Psychology, 26, 108-123.

Oyserman, D., Uskul, A. K., Yoder, N., Nesse, R. M., \& Williams, D. R. (2007). Unfair treatment and self-regulatory focus. Journal of Experimental Social Psychology, 43, $505-$ 512.

Posthuma, R. A., Maertz, C. P., \& Dworkin, J. B. (2007). Procedural justice's relationship with turnover: Explaining past inconsistent findings. Journal of Organizational Behavior, 28, 381-398. 
Sassenberg, K., \& Hansen, N. (2007). The impact of regulatory focus on affective responses to social discrimination. European Journal of Social Psychology, 37, 421-444.

Scheier, M. F., Buss, A. H., \& Buss, D. M. (1978). Self-consciousness, self-reports of aggressiveness, and aggression. Journal of Research in Personality, 12, 133-140.

Sedikides, C., \& Brewer, M. B. (2001a). Individual self, relational self, collective self. Philadelphia, PA: Psychology Press.

Sedikides, C., \& Brewer, M. B. (2001b). Individual, relational, and collective self: Partners, opponents, or strangers? In C. Sedikides \& M. B. Brewer (Eds.). Individual self, relational self, collective self (pp. 1-4). Philadelphia, PA: Psychology Press.

Sedikides, C., Hart, C., M., \& De Cremer, D. (in press). The self in procedural fairness. Social and Personality Psychology Compass.

Sedikides, C., De Cremer, D., Hart, C. M., \& Brebels, L. (in press). Procedural fairness responses in the context of self-uncertainty. In R. M. Arkin, K. C. Oleson, \& P. J. Carroll (Eds.), The uncertain self: A handbook of perspectives from social and personality psychology. Mahwah, NJ: Lawrence Erlbaum Associates.

Sedikides, C., \& Gregg, A. P. (2003). Portraits of the self. In M. A. Hogg \& J. Cooper (Eds.), Sage handbook of social psychology (pp. 110-138). London: Sage Publications.

Sedikides, C., \& Gregg, A. P. (2008). Self-enhancement: Food for thought. Perspectives on Psychological Science, 3, 102-116.

Sedikides, C., \& Strube, M. J. (1997). Self-evaluation: To thine own self be good, to thine own self be sure, to thine own self be true, and to thine own self be better. In M. P. Zanna (Ed.), Advances in Experimental Social Psychology, 29, 209-269. New York, NY: Academic Press. 
Seibt, B., \& Förster, J. (2004). Stereotype threat and performance: how stereotypes influence processing by inducing regulatory foci. Journal of Personality and Social Psychology, $87,38-56$.

Skarlicki, D. P., \& Folger, R. (1997). Retaliation in the workplace: The roles of distributive, procedural, and interactional justice. Journal of Applied Psychology, 82, 434-443.

Skitka, L. J. (2002). Do the means always justify the ends, or do the ends sometimes justify the means?: A value protection model of justice reasoning. Personality and Social Psychology Bulletin, 28, 588-597.

Skitka, L. J. (2003). Of different minds: An accessible identity approach to why and how people think about justice. Personality and Social Psychology Review, 7, 286-297.

Skitka, L. J., \& Bravo, J. (2005). An accessible identity approach to understanding fairness in organizational settings. In K. Van den Bos, D. Steiner, D. Skarlicki, \& S. Gilliland (Eds.), What motivates fairness in organizations? (pp. 105-128). Greenwich, CT: Information Age Publishing.

Stapel, D. A., \& Van der Zee, K. I. (2006). The self salience model of other-to-self effects: Integrating principles of self-enhancement, complementarity, and imitation. Journal of Personality and Social Psychology, 90, 258-271.

Sutton, S. K., \& Davidson, R. J. (1997). Prefrontal brain asymmetry: A biological substrate of the behavioral approach and inhibition systems. Psychological Science, 8, 204-210.

Tripp, T.M., \& Bies, R.J. (1997). What's good about revenge?: The avenger's perspective. In R.J. Lewicki, R.J. Bies, \& B.H. Sheppard (Eds.), Research on negotiation in organizations (Vol. 6, pp. 145-160). Greenwich, CT: JAI Press.

Tyler, T. R., \& Blader, S. L. (2000). Cooperation in groups: Procedural justice, social identity, and behavioral engagement. Philadelphia, PA: Taylor \& Francis. 
Tyler, T. R., \& Lind, E. A. (1992). A relational model of authority in groups. In M. Zanna (Ed.), Advances in experimental social psychology (Vol. 25, pp. 115-191). New York, NY: Academic Press.

Utz, S. (2004). Self-activation is a two-edged sword: The effects of I-primes on cooperation. Journal of Experimental Social Psychology, 40, 769-776.

Van-Dijk, D., \& Kluger, A. (2004). Feedback sign effect on motivation: Is it moderated by regulatory focus? Applied Psychology: An International Review, 53, 113-135.

Van den Bos, K. (2001). Fundamental research by means of laboratory experiments is essential for a better understanding of organizational justice. Journal of Vocational Behavior, 58, 254259.

Van den Bos, K. (2007). Hot cognition and social justice judgments: The combined influence of cognitive and affective factors on the justice judgment process. In D. De Cremer (Ed.), Advances in the psychology of justice and affect (pp. 59-82). Greenwich, CT: Information Age Publishing.

Van den Bos, K., \& Lind, E. A. (2002). Uncertainty management by means of fairness judgments. In M. P. Zanna (Ed.), Advances in experimental social psychology (Vol. 34, pp. 1-60). San Diego, CA: Academic Press.

Van den Bos, K., \& Miedema, J. (2000). Toward understanding why fairness matters: The influence of mortality salience on reactions to procedural fairness. Journal of Personality and Social Psychology, 79, 355-366.

Van den Bos, K., Vermunt, R., \& Wilke, H. (1997). Procedural and distributive justice: What is fair depends more on what comes first than on what comes next. Journal of Personality and Social Psychology, 72, 95-104. 
Van den Bos, K., Bruins, J., Wilke, H. A. M., \& Dronkert, E. (1999). Sometimes unfair procedures have nice aspects: On the psychology of the fair process effect. Journal of Personality and Social Psychology, 77, 324-366.

Van Prooijen, J.-W., Karremans, J. C., Van beest, I. (2006). Procedural justice and the hedonic principle: How approach versus avoidance motivation influences the psychology of voice. Journal of Personality and Social Psychology, 91, 686-697.

Van Prooijen, J.-W., Van den Bos, K., Lind, E. A., \& Wilke, H. A. M. (2006). How do people react to negative procedures?: On the moderating role of authority's biased attitudes. Journal of Experimental Social Psychology, 42, 632-645.

Verplanken, B., \& Holland, R. W (2002). Motivated decision making: Effects of activation and self-centrality of values on choices and behavior. Journal of Personality and Social Psychology, 82, 434-447.

Werth, L., \& Förster, J. (2007). How regulatory focus influences consumer behavior. European Journal of Social Psychology, 37, 33-51. 


\section{Author Note}

Lieven Brebels and David De Cremer, Tilburg University, The Netherlands; Constantine Sedikides, University of Southampton, England, UK.

Correspondence concerning this manuscript should be addressed to Lieven Brebels, Department of Social Psychology, Center of Justice and Social Decision Making (JuST; www.centerofjust.com), Tilburg University, P.O. Box 90153, 5000-LE Tilburg, The Netherlands; Email: L.Brebels@uvt.nl

This research was supported by a research grant from the Netherlands Organization for Scientific Research (NWO, Grant No. 016-005.019) awarded to the second author. 
Table 1

Retaliation as a Function of Procedural Fairness and Regulatory Focus in Study 2.

$\beta \quad R \quad R^{2} \quad R_{\text {adj }}^{2} \quad R_{\text {change }}^{2} d f$

Dependent Variable

Retaliation

Step 1

.51

.26

.23

.26

3,67

gender

$.41^{* * *}$

procedural fairness

.11

regulatory focus

$-.23^{*}$

Step 2

.57

.32

.28

.06

4, 66

procedure $\mathrm{x}$

$.24^{*}$

regulatory focus

Note. Total $F(4,66)=7.76, p<.001$.

${ }^{*} p<.05,{ }^{* * *} p<.001$ 
Table 2

Retaliation as a Function of Individual Self-Focus and Regulatory Focus in Study 4.

$\beta \quad R \quad R^{2} \quad R_{\text {adj }}^{2} \quad R_{\text {change }}^{2} d f$

Dependent Variable

Retaliation

Step 1

gender

individual self-focus

regulatory focus

Step 2

individual self-focus $\mathrm{x}$

$.26^{*}$

regulatory focus

.15

$-.19$

$-.20$
.32

.10

.06

.10

3,74

Note. Total $F(3,74)=3.13, p<.05$.

${ }^{*} p<.05$
.41

.17

.12

.07

4,73

.12


Unfair Treatment, Retaliation, and Self-Regulation 51

\section{Figure Captions}

Figure 1. Retaliation as a Function of Procedural Fairness and Regulatory Focus in Study 1.

Figure 2. Retaliation as a Function of Procedural Fairness and Regulatory Focus in Study 2.

Figure 3. Retaliation as a Function of Regulatory Focus and Individual-Self Accessibility in Study 4.

Figure 4. Retaliation as a Function of Regulatory Focus and Individual-Self Accessibility in Study 5. 
Figure 1

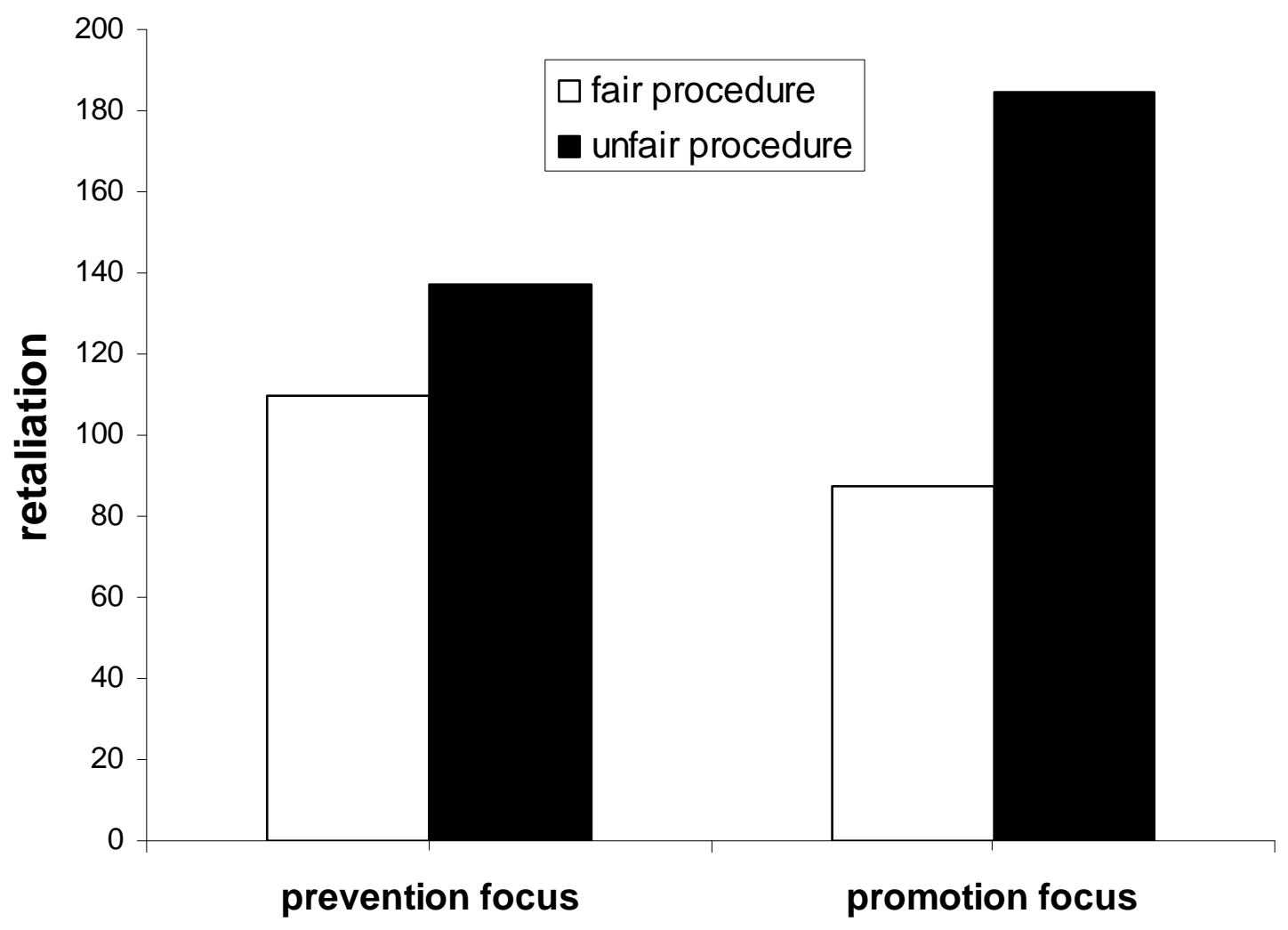


Figure 2

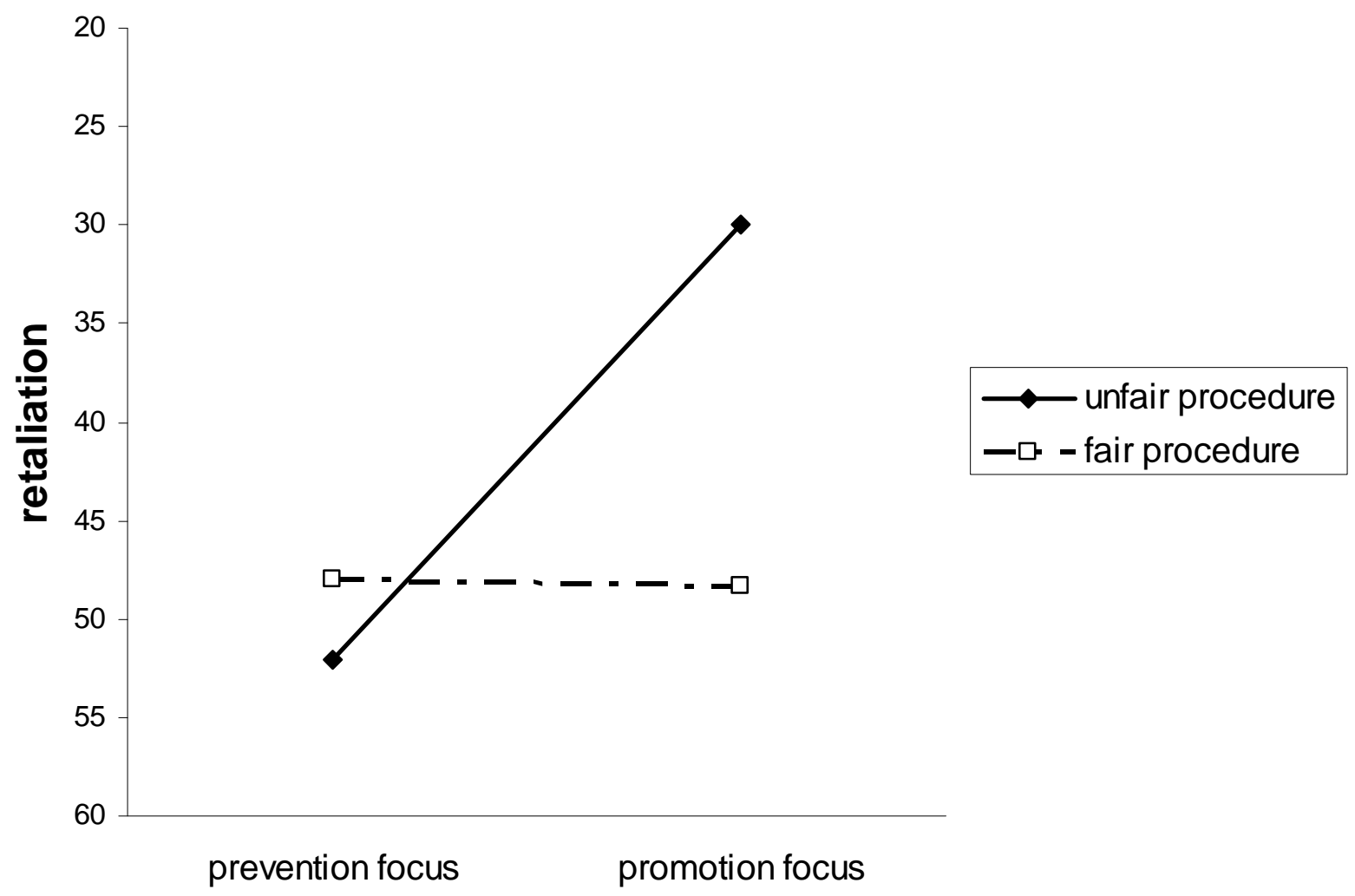


Figure 3

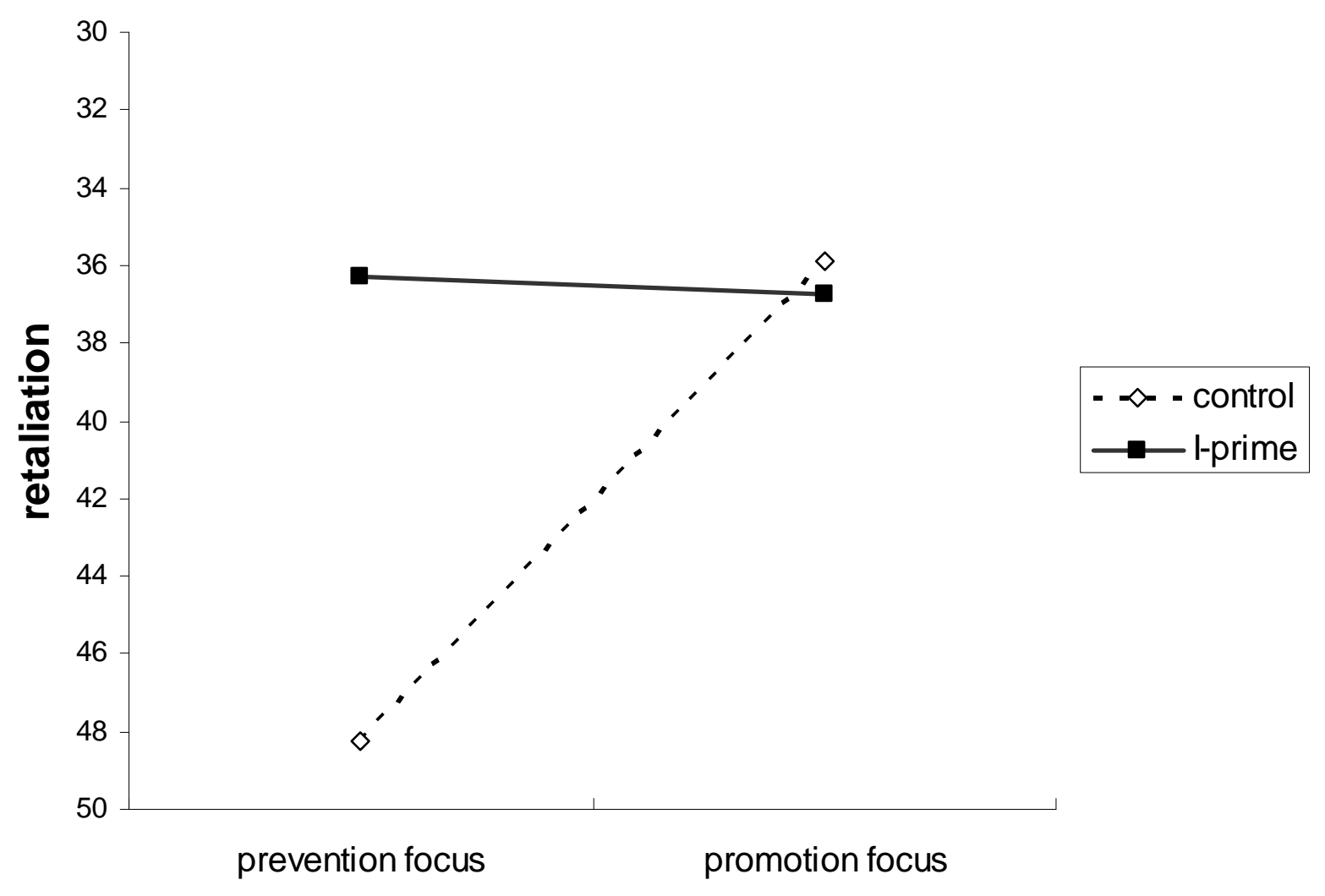


Figure 4

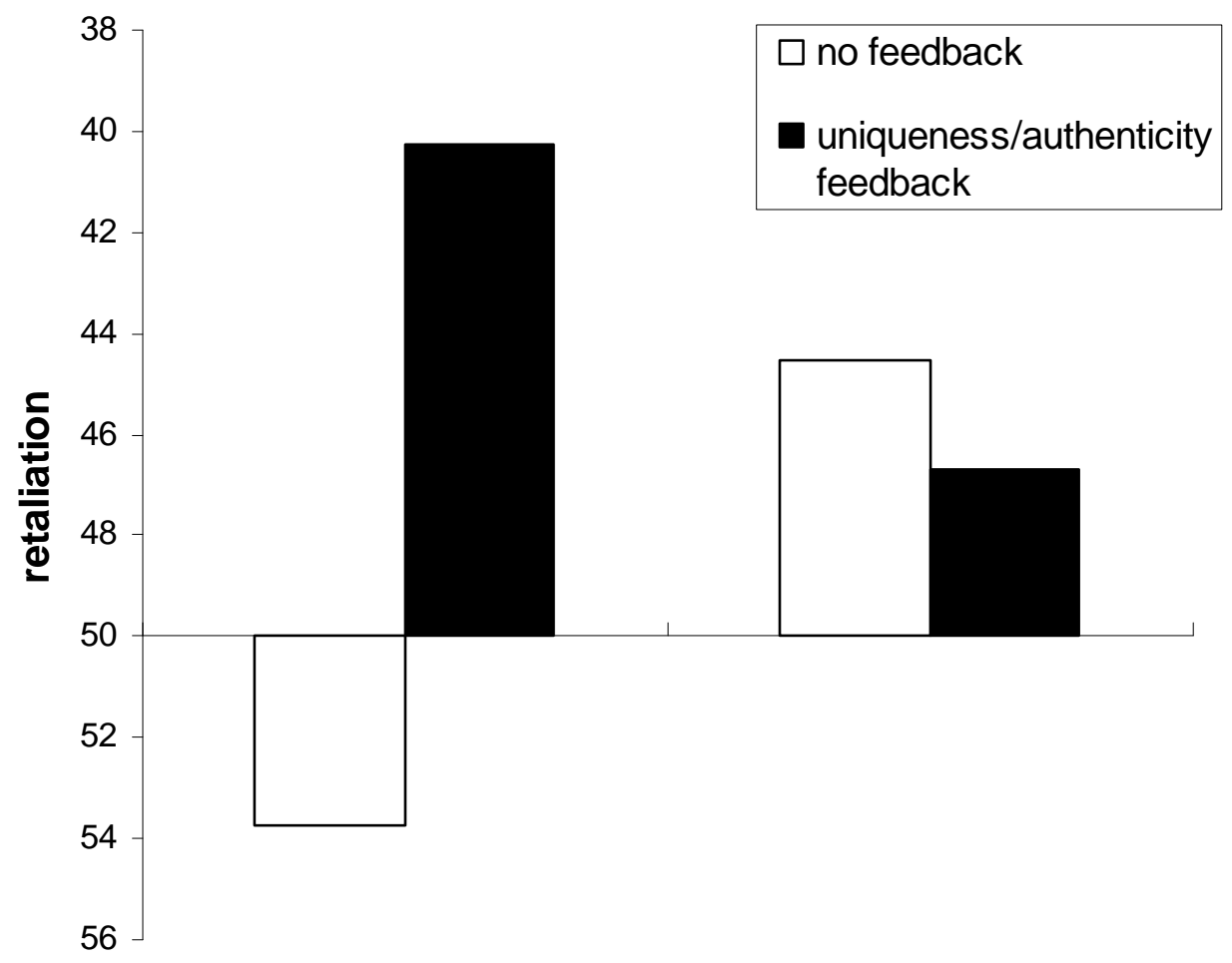

prevention focus promotion focus 